\title{
Structural reliability assessment of accidentally damaged oil tanker
}

\author{
B. Bužančić Primorac \\ Faculty of Electrical Engineering, Mechanical Engineering and Naval Architecture, University of Split, \\ Split, Croatia
}

J. Parunov

Faculty of Mechanical Engineering and Naval Architecture, University of Zagreb, Zagreb, Croatia

\begin{abstract}
The methodology for the structural reliability assessment of oil tanker damaged in collision and grounding accidents is proposed in the paper. The approach is consistent with International Maritime Organization (IMO) structural reliability assessment of intact oil tankers. The main extension of the structural reliability analysis of the intact ship is that the loss of the ultimate longitudinal strength and the increase of the still water bending moment in damaged condition are considered as random variables. The probability distributions of these random variables are defined based on damage parameters proposed by IMO. The methodology is applied on the example of the Aframax oil tanker resulting in the failure probabilities comparable to the other similar studies. The advantages of the presented approach are its simplicity and consistency with IMO recommendations. Sensitivity analysis is performed that enables identification of the most important parameters for structural safety of damaged ships. The methodology may efficiently be applied in the risk assessment studies of the maritime transportation as well as for calibration of partial safety factors in the ship structural rules.
\end{abstract}

\section{INTRODUCTION}

The structural failure of the oil tanker may occur due to unfavorable environmental conditions or due to human errors during the design or operation of the ship. The most frequent ways of tanker accidents are collision with another ship or grounding. In case of such an accident, the ship strength could be significantly reduced while still water loads increase and wave loads could become considerable cause of the structural overloading. A damaged oil tanker may collapse after a collision or grounding if she does not have adequate longitudinal strength. Such collapse can occur when the hull's maximum load-carrying capacity is insufficient to sustain the corresponding hull-girder loads applied (Luis et al. 2007; Hussein and Guedes Soares 2009; Prestileo et al. 2013).

Ship structural designers are unavoidably faced with the question how ship structure would behave in case of an accident. The aim is to avoid breaking of the ship in two parts and sinking of the ship even if the ultimate bending moment capacity is reduced because of the damage. However, ship damage may occur in a number of ways, while parameters used to describe damage, so-called damage parameters, are random quantities. Consequently, changes in the ultimate bending moment capacity of the damaged vessel and in Still Water Bending Moment (SWBM) are also random variables depending on the probability distributions of the damage parameters (damage size and location). International Maritime Organization (IMO 2003) proposed such probability distributions for cases of the collision and grounding of oil tankers, based on available tanker casualty statistics.

The reliability formulation presented by Parunov and Guedes Soares (2008) is adopted for the intact ship. That methodology for the intact oil tanker is consistent with the structural reliability assessment proposed by IMO (2006) and it results in very similar failure probabilities. In the present study, the procedure is slightly extended for the reliability assessment of damaged ship. The extension consists of introducing random variables for reduction of the ultimate strength caused by loss of structural elements due to damage only and for the factor of increase of SWBM for damaged ship. The probabilistic models of these newly introduced random variables are based on the recent researches (Bužančić Primorac and Parunov 2015, Bužančić Primorac et al. 2015). Bases for definition of these probabilistic models are random damage parameters defined by IMO (2003). The model of the extreme wave load is also modified, to take into account relatively short time needed for ship salvage operation, during which damaged ship is still exposed to waves.

The methodology is employed on the Aframax oil tanker. The safety index is calculated using the 
First-Order Reliability Method (FORM) for intact and damaged ship. Sensitivity analysis is performed to investigate the influence of uncertainties of pertinent random variables on safety indices. Design points are determined representing the most probable values of random variables in the case of the failure. Finally, discussion on results and conclusions are provided.

\section{DESCRIPTION OF THE ANALYSED SHIP}

Ship analysed in present study is Aframax doublehull oil tanker with main particulars presented in Table 1, general arrangement shown in Figure 1 and midship section in Figure 2. In longitudinal

Table 1. Main particulars of Aframax tanker.

\begin{tabular}{lc}
\hline Dimension & Unit (m, dwt) \\
\hline Length between perp., LPP & 234 \\
Breadth, $B$ & 40 \\
Depth, $D$ & 20 \\
Draught, $T$ & 14 \\
Deadweight, DWT & 105000 \\
\hline
\end{tabular}

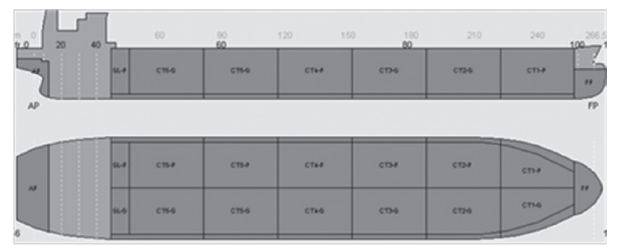

Figure 1. General arrangement of Aframax tanker.

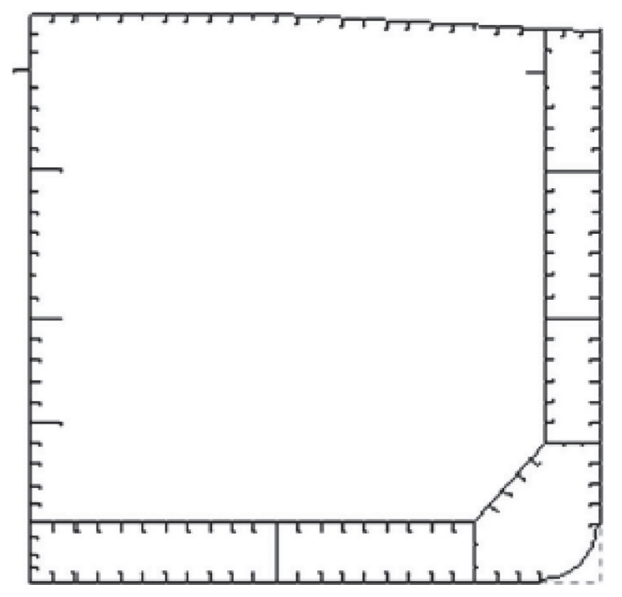

Figure 2. Midship section of Aframax tanker. sense, cargo tank area is divided into six pairs of oil tanks as well as corresponding pairs of water ballast tanks.

\section{RELIABILITY FORMULATION}

By applying the reliability methods in assessment of the structural safety, structural strength components and load effect components are considered as random variables. The demand and the structural capacity are related through a mathematical expression, known as the limit state function, which defines whether the structure fulfils its intended purpose regarding the particular failure criterion or not.

The limit-state function with respect to the hull-girder ultimate failure under vertical bending moments, considered in the present study, reads

$\chi_{u} R I F M_{u 0}-\left(K_{U S} M_{s w}+K_{U W} \psi \chi_{w} \chi_{n l} M_{w}\right)<0$

where $M_{u}$ is the random variable ultimate hullgirder bending moment of the damaged ship; $R I F$ the random variable residual strength index $(R I F=1$ for intact ship and for intact section of damaged ship); $M_{u 0}$ the deterministic ultimate hull-girder bending moment of the intact ship; $M$ the random variable extreme vertical stillwater bending moment in the reference period (1 year); $M_{w}$ the random variable extreme vertical wave bending moment in the reference period; $K_{U S}$ the random variable representing increase of the still-water load of damaged ship (for intact ship, $\left.K_{U S}=1\right) ; K_{U W}$ the deterministic factor of reduction of wave load of damaged ship $\left(K_{U W}=1\right.$ for intact ship); $\psi$ the deterministic load combination factor between extreme still-water loads and extreme wave loads; $\chi_{u}, \chi_{w}, \chi_{n l}$ the random variables representing the modelling uncertainty of ultimate strength, linear wave load and non-linearity of wave load.

The reliability analysis according to the limitstate equation (1) is performed only for one failure mode - sagging and for only one elementary loading condition-Full Load condition (FL). Safety indices $\beta$ and associated failure probabilities $P_{f}$ are calculated for intact ship and for ship damaged in random collision or grounding accidents. In the case of damaged ship, distinguish is made between intact and damaged section of damaged ship. Following this, five different safety indices and associated failure probabilities are calculated.

As demonstrated by Parunov and Guedes Soares (2008), the presented approach for the case of the intact oil tanker is consistent with approach adopted by IMO (2003) resulting in comparable yearly failure probabilities. 


\section{UNCERTAINTY MODELLING}

\subsection{Ultimate vertical bending moment}

The ultimate hull-girder bending moment capacity is defined as the maximum bending moment of the hull-girder beyond which the hull will collapse. This moment, generally between the elastic and the plastic moment, is the sum of the contribution of longitudinally effective elements, i.e. the sum of the first moments of the bending stresses around the horizontal neutral axes. The ultimate bending moment capacity calculation for intact ship is performed by Parunov and Guedes Soares (2008) using Progressive Collapse Analysis (PCA) and it reads $8246 \mathrm{MNm}$ for the intact ship in sagging, while the modified Paik-Mansour method is employed for residual strength assessment of the damaged ship (Paik et al. 2011). The limitation of the method employed is that the rotation of the neutral axis due to side damage is neglected, based on the conclusion from Muhammad Zubair $\mathrm{PhD}$ thesis (2013), stating that the reduction ratio of the residual hull girder strength due to the rotation of the neutral axis is almost negligible for the case of oil tankers having outer shell damage. This assumption is potentially un-conservative, especially for huge side damages.

The random reduction of the ultimate bending moment for ship damaged by grounding or collision is calculated by Monte Carlo simulation, assuming that the damage parameters are random variables described by probability density functions proposed by IMO (2003) (Fig. 3). The nondimensional grounding damage parameters are defined as transverse damage location $\left(x_{1}\right)$, damage height $\left(x_{2}\right)$, damage breadth $\left(x_{3}\right)$ and angle of the rock $\left(x_{4}=\varphi\right)$, while the non-dimensional collision damage parameters are defined as transverse damage extent $\left(x_{1}\right)$, vertical damage extent $\left(x_{2}\right)$ and vertical damage location $\left(x_{3}\right)$. Grounding damage is assumed to be caused by conically shaped rock and reduction of ultimate strength is calculated by design equations using the concept of Grounding Damage Index (GDI) (Kim et al. 2013), while

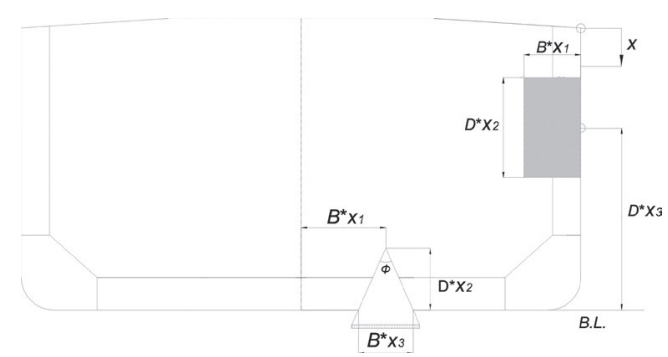

Figure 3. Location and extent of grounding and collision damages. collision damage is assumed as rectangular box and design equations developed by Bužančić Primorac and Parunov (2015) are used for ultimate strength reduction calculation.

The random loss of the ultimate bending capacity of damaged ship $\left(M_{u l o s s^{\circ} \%}\right)$ is expressed as the percentage of the ultimate hull-girder bending moment of the damaged ship $\left(M_{u D}\right)$ with respect to the ultimate hull-girder bending moment of the intact $\operatorname{ship}\left(M_{u 0}\right)$ as:

$M_{u l o s s} \%=\left(1-\frac{M_{u D}}{M_{u 0}}\right) \cdot 100$

$M_{u l o s s}$ may be represented by the exponential distribution, while parameters of the distributions are given in Table 2 and the related histograms with fitted exponential functions are shown in Figure $4 \mathrm{a}$ and $4 \mathrm{~b}$, for grounding and collision damage respectively (Bužančić Primorac and Parunov 2015).

As the fitted distributions represent the random variable loss of ultimate bending moment, the residual strength index $(R I F)$, appearing in Equation 1 , is also random variable expressed as function of relative loss of ultimate bending moment (Equation 2) by Equation 3:

$R I F=\frac{M_{u D}}{M_{u 0}}=1-\frac{M_{u l o s s} \%}{100}$

This expression for RIF is therefore included in the limit-state function (Equation 1).

All uncertainty in the prediction of the ultimate strength is concentrated in a model uncertainty random variable $\chi_{u}$, which takes into account both the uncertainty in the yield strength and the model uncertainty of the method to assess the ultimate capacity of the midship section, as both variables contribute to the ultimate bending moment. $\chi_{u}$ is defined as a log-normal distribution with a mean value of 1.1 and coefficient of variation of 0.12 (Parunov and Guedes Soares 2008).

\subsection{Still-water bending moment}

A Gaussian distribution is used as the stochastic model of the still-water bending moment for one voyage. The mean value and standard devia-

Table 2. Parameters of distribution for loss of UBM (\%).

\begin{tabular}{lll}
\hline Damage & Distribution & Mean \\
\hline Grounding & Exponential & 4.160 \\
Collision & Exponential & 3.453 \\
\hline
\end{tabular}


a)

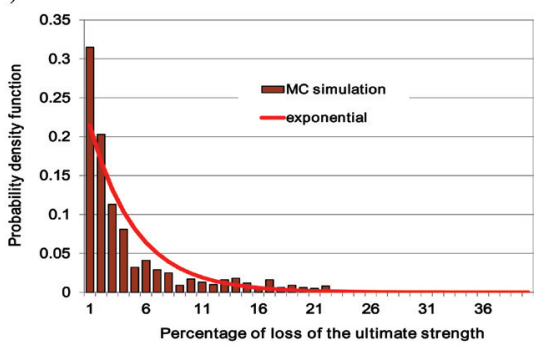

b)

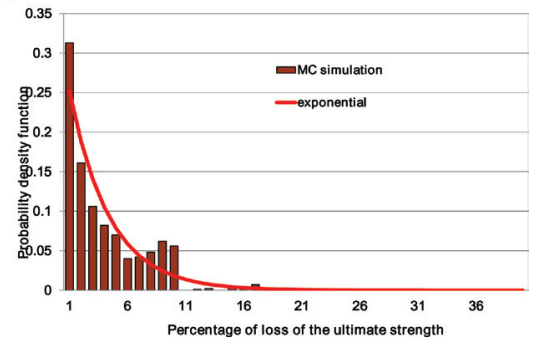

Figure 4. Histograms of losses of the ultimate strength with fitted exponential function for a) grounding damage $(\bar{x}=4.160)$; b) collision damage $(\bar{x}=3.453)$.

tion for full load condition, which is here considered, were calculated from the loading manual, first separately for departure and arrival conditions, and then the resulting normal distribution is obtained as average value.

When the mean value $\mu_{s w}$ and the standard deviation $\sigma_{s w}$ of normal distribution are known, the extreme value distribution for a given time period $T_{C}$ may be approximated using a Gumbel distribution with the following parameters:

$x_{e}^{*}=F_{s w}^{-1}\left(1-\frac{1}{n_{s w}}\right), \alpha=\frac{1-F_{s w}}{f_{s w}}$

where $n_{s w}$ is the mean number of voyages in the full load condition in the reference period $T_{C}$ (1 year) $\left(n_{s w}=5.4\right), F_{s w}$ is the cumulative probability distribution and $F_{s w}^{-1}$ its inverse, while $f_{s w}$ is the probability density function of normal distribution with parameters $\mu_{s w}$ and $\sigma_{s w}$. The mean value $\mu_{s e}$ and standard deviation $\sigma_{s e}$ of the Gumbel distribution are then given as

$\mu_{e}=x_{e}^{*}+\alpha \times 0.5772$,

$\sigma_{e}=\frac{\pi}{\sqrt{6}} \alpha$

Parameters of the stochastic model of the stillwater bending moment for full load condition, for duration of one voyage and period of one year are presented in Table 3.
Above presented procedure and its results are adopted for the intact ship (Parunov and Guedes Soares 2008), while for damaged ship the random factor $K_{U S}$ of increase of SWBM is here introduced. The random $K_{U S}$ is presented in the form of histograms that may be reasonably fitted with normal distribution (Bužančić Primorac et al. 2015). Parameters of the normal distributions are given in Table 4 and the related histograms with fitted normal distributions are shown in Figures 5 and 6, for collision and grounding, and for intact and damaged section of damaged ship.

\subsection{Vertical wave bending moment}

Evaluation of the wave-induced load effects that can occur during long-term operation of the intact ship in a seaway was carried out for sea areas in the North Atlantic in accordance with the IACS Recommendation Note No. 34 (IACS 2000). This recommendation is aimed as guidance for usage of hydrodynamic analysis for computation of extreme wave loads of ships covered by UR S11.

The calculation of transfer functions of waveinduced load effects is made with the program WADAM, based on the sink-source 3D method. The long-term analysis according to the IACS procedure is performed for full load condition by the computer program POSTRESP, which is part of the SESAM package.

The probability that the response amplitude remains less than a given value $x_{e}$ over a longer time period, e.g. 1 voyage, 1 year or 20 years, is given by the Gumbel law:

$$
F\left(x_{e}\right)=e^{-e^{\left(-\left(x_{e}-x_{e}^{*} / \alpha\right)\right)}}
$$

Table 3. Parameters of SWBM distribution $(\mathrm{MNm})$.

\begin{tabular}{lllll}
\hline $\begin{array}{llll}\text { One voyage } \\
\text { (Gaussian) }\end{array}$ & & \multicolumn{2}{l}{$\begin{array}{l}\text { One year } \\
\text { (Gumbel) }\end{array}$} \\
\cline { 1 - 1 } \cline { 5 - 5 }$\mu_{s w}$ & $\sigma_{s w}$ & & $\mu_{s e}$ & $\sigma_{s e}$ \\
\hline-1229 & 456 & & -1819 & 405 \\
\hline
\end{tabular}

Table 4. Parameters of distributions of $K_{U S}$ for damaged ship.

\begin{tabular}{lll}
\hline Damage condition & $\begin{array}{l}\text { Mean } \\
\text { value }\end{array}$ & $\begin{array}{l}\text { Standard } \\
\text { deviation }\end{array}$ \\
\hline Collision (overall) & 0.88 & 0.45 \\
Collision (damaged area) & 0.76 & 0.55 \\
Grounding (overall) & 0.60 & 0.86 \\
Grounding (damaged area) & 0.58 & 0.85 \\
\hline
\end{tabular}


a)

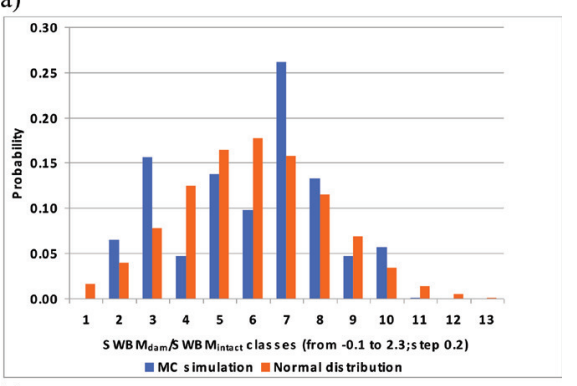

b)

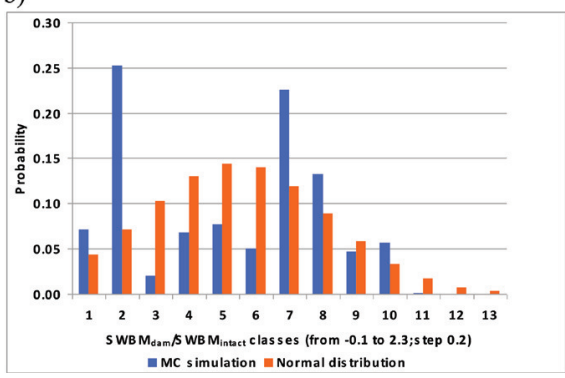

Figure 5. Histograms and normal distributions of $K_{U S}$ after collision damage a) overall maximum $K_{U S}$; b) maximum $K_{U S}$ in the area of damaged tanks.

where parameters $x_{e}^{*}$ and $\alpha$ are derived from the scale parameter $\theta$ and the shape parameter $\lambda$ of the Weibull distribution, which is an excellent approximation of the amplitude of various ship responses in waves, by following relationships:

$\alpha=\frac{\theta}{\lambda}(\ln n)^{(1-\lambda) / \lambda}$

$x_{e}^{*}=\theta(\ln n)^{1 / \lambda}$

where $n$ is the number of response cycles in a given long-term period, while $x_{e}^{*}$ is the most probable extreme value in $n$ cycles.

The mean value and the standard deviation of Gumbel distribution are already defined by Equations 5 and 6 . Gumbel distribution obtained by this procedure is actually the inherent uncertainty of the extreme vertical wave bending moment, as represented by the random variable $M_{w}$ in Equation 1. Stochastic model of the vertical wave-induced bending moment for the full load condition is described in Table 5 (Parunov and Guedes Soares 2008).

Simplifications, assumptions and inaccuracies of the linear engineering models used to predict extreme wave loads on ship hulls are taken into account by the modeling uncertainty $\chi_{w}$, which appears in Equation 1. For the need of the present study, $\chi_{w}$ is assumed to be a normally distributed random variable with the mean value equal to 1 and
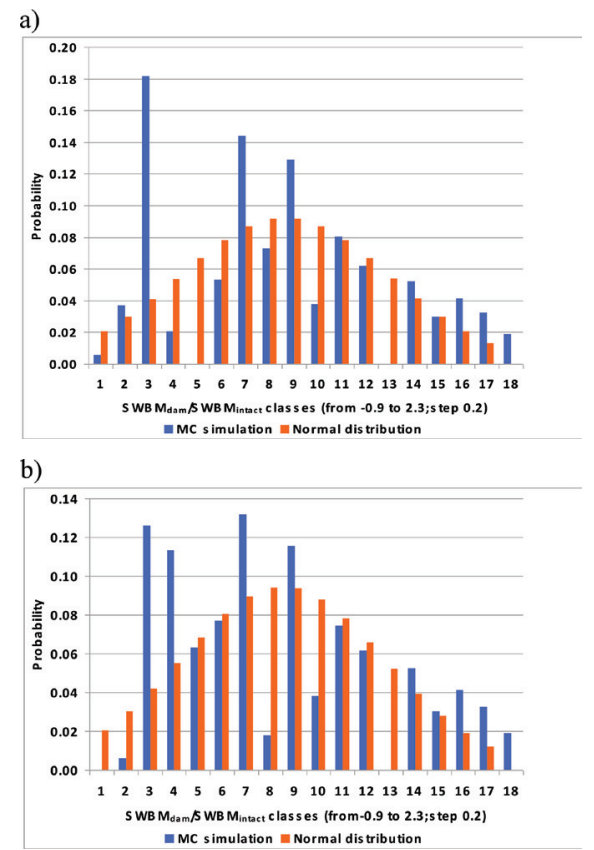

Figure 6. Histograms and normal distributions of $K_{U S}$ after grounding damage a) overall maximum $K_{U S} ;$ b) maximum $K_{U S}$ in the area of damaged tanks.

Table 5. Stochastic model of vertical wave bending moment (MNm).

\begin{tabular}{llllll}
\hline \multicolumn{2}{l}{ Weibull parameters } & & \multicolumn{3}{l}{ Gumbel moments (1 year) } \\
\cline { 1 - 1 } \cline { 5 - 6 }$\theta$ & $\lambda$ & & $n$ & $\mu_{e}$ & $\sigma_{e}$ \\
\hline 218.2 & 0.96 & & $1.07 \times 10^{6}$ & 3526 & 325.3 \\
\hline
\end{tabular}

coefficient of variation equal to 0.1 . The effect of the non-linearity of the response is particularly significant for ships with a low block coefficient, leading to differences between sagging and hogging bending moments. The uncertainty of non-linear effects $\chi_{n l}$ is assumed to be a normally distributed variable with mean value equal to non-linear correction factors proposed by IACS UR S11, while the coefficient of variation of this uncertainty is assumed to be 0.15 (Parunov and Guedes Soares 2008).

For damaged ship, factor of decrease of the wave load $K_{U W}$ that appears in Equation (1) is introduced. It reads 0.85 and it is based on direct calculations of wave loads in European coastal seas for exposure period of 7 days (Teixeira \& Guedes Soares 2010).

\subsection{Load combinations}

The reliability assessment depends on the combination of the extreme still-water and wave loads. The combined load is usually less than the sum of two 
maxima that can occur at any time. Having defined the probabilistic models for extreme still-water and wave-induced bending moment, the prediction of the combined loads should be assessed taking into account the random nature of the loads. Therefore, the load combination factor $\psi$ is introduced, and for full load condition it reads 0.92 (Guedes Soares and Teixeira 2000).

\section{RESULTS OF THE RELIABILITY ANALYSIS}

The summary of the stochastic models adopted for random variables and the deterministic values is presented in Table 6 .

\subsection{Safety indices and failure probabilities}

Safety indices $\beta$ and associated failure probabilities $P_{f}$ are calculated for sagging failure mode and for full load condition. Calculated values for intact ship and for intact and damaged section of ship damaged by collision and grounding are presented in Table 7.

It is interesting to notice from Table 7 that the reliability indices of damaged ships are slightly lower compared to the intact ship. The reliability index for grounding is lower than for collision. Also, reliability index for damaged area is lower compared to the intact region of damaged ship. This is despite the fact that SWBM model employed for intact area is higher compared to the damaged area (see Table 4).

\subsection{Sensitivity analysis}

Sensitivity analysis is performed by calculating the normalized sensitivity factors $\alpha_{i}$, which are presented in Tables 8-10 and in Figures 7-9. In the same tables the coordinates of the design point $x_{i}^{*}$, representing the most probable combination of random variables in the case of failure, are included.

\subsection{Parametric study}

The parametric study is performed for sagging failure mode of damaged ship in full load condition. This is done in order to get better insight into sensitivity of the procedure to the input parameters. The variation of two parameters is performed, $M_{\text {unso }}$ the random loss of the ultimate bending capacity of damaged ship and $K_{U S}$ - the random increase of the still water load of damaged ship. Only one of the parameters is varied in each reliability analysis, while all the others retain their "best estimate" values as specified in Table 6 . The parameters' intervals limits are calculated for corresponding mean values $\bar{x}$ of $M_{u l o s s^{\prime} \%}$ and $K_{U S}$ for collision and grounding damage respectively, as the $95 \%$ confidence interval by the conventional approach (central limit theorem) (Bužančić Primorac and Parunov 2015).
Table 6. Summary of stochastic model adopted.

\begin{tabular}{lllll}
\hline Variable & Damage & Distribution & Mean & COV \\
\hline$M_{u}(\mathrm{MNm})$ & & Deterministic & 8246 & \\
$M_{u l o s s}$ & Collision & Exponential & 0.035 & \\
& Grounding & $\begin{array}{l}\text { Exponential } \\
M_{s w}(\mathrm{MNm})\end{array}$ & 0.042 & \\
$M_{w}(\mathrm{MNm})$ & & Gumbel & 1819 & 0.22 \\
$K_{U S}$ & Gumbel & 3526 & 0.09 \\
& $\begin{array}{c}\text { Collision } \\
\text { (overall) }\end{array}$ & Gaussian & 0.88 & 0.51 \\
& $\begin{array}{c}\text { Collision } \\
\text { (damaged }\end{array}$ & Gaussian & 0.76 & 0.72 \\
& $\begin{array}{l}\text { area) } \\
\text { Grounding } \\
\text { (overall) }\end{array}$ & Gaussian & 0.60 & 1.43 \\
& Grounding & Gaussian & 0.58 & 1.47 \\
& (damaged & & & \\
$K_{U W}$ & area) & Deterministic & 0.85 & \\
$\Psi$ & & Deterministic & 0.92 & \\
$\chi_{u}$ & & Log-normal & 1.1 & 0.12 \\
$\chi_{w}$ & & Gaussian & 1.0 & 0.1 \\
$\chi_{n l}$ & & Gaussian & 1.03 & 0.15 \\
\hline
\end{tabular}

Table 7. Safety indices and failure probabilities for intact and damaged ship.

\begin{tabular}{lll}
\hline Damage condition & $\beta$ & $P_{f}$ \\
\hline Intact & 3.043 & $1.171 \mathrm{E}-03$ \\
Collision (intact area) & 2.925 & $1.721 \mathrm{E}-03$ \\
Collision (damaged area) & 2.741 & $3.067 \mathrm{E}-03$ \\
Grounding (intact area) & 2.422 & $7.718 \mathrm{E}-03$ \\
Grounding (damaged area) & 2.346 & $9.492 \mathrm{E}-03$ \\
\hline
\end{tabular}

Table 8 . Sensitivity factors and coordinates of design point for intact ship.

\begin{tabular}{llllll}
\hline & $\chi_{u}$ & $\chi_{w}$ & $\chi_{n l}$ & $M_{w}$ & $M_{s w}$ \\
\hline$\alpha_{i}(\%)$ & 28.3 & 14.6 & 20.1 & 18.3 & 18.7 \\
$x_{i}{ }^{*}$ & 0.85 & 1.10 & 1.24 & 3911 & -2316 \\
\hline
\end{tabular}

The results of the parametric study are presented in Tables 11 and 12. It may be seen that the variation of the $M_{\text {uloss } \%}$ results in lower variability of the safety indices, compared to the variation of the $K_{U S}$. Also, comparing the values for safety indices from Tables 7 and 12 , it can be concluded that variation of the $K_{U S}$ gives somewhat higher variability for ship damaged by grounding than for the collision damage.

\section{DISCUSSION}

It is interesting to compare obtained results to the other similar studies. Failure probabilities in Table 7 for grounding are between values calculated by Prestileo (2013) of 1.785E-02 and 5.419E-04 for 
Table 9. Sensitivity factors and coordinates of design point for ship damaged by collision (damaged area).

\begin{tabular}{llllllll}
\hline & $\chi_{u}$ & $\chi_{w}$ & $\chi_{n l}$ & $M_{w}$ & $M_{s w}$ & $M_{\text {uloss }}$ & $K_{U S}$ \\
\hline$\alpha_{i}(\%)$ & 19.3 & 6.8 & 9.8 & 6.5 & 22.8 & 6.1 & 28.7 \\
$x_{i}{ }^{*}$ & 0.94 & 1.04 & 1.12 & 3654 & -2387 & 0.05 & 1.74
\end{tabular}

Table 10. Sensitivity factors and coordinates of design point for ship damaged by grounding (damaged area).

\begin{tabular}{llllllll}
\hline & $\chi_{u}$ & $\chi_{w}$ & $\chi_{n l}$ & $M_{w}$ & $M_{s w}$ & $M_{\text {uloss }}$ & $K_{U S}$ \\
\hline$\alpha_{i}(\%)$ & 17.6 & 5.8 & 8.4 & 5.2 & 21.0 & 6.5 & 35.6 \\
$x_{i}^{*}$ & 0.98 & 1.03 & 1.10 & 3609 & -2241 & 0.06 & 2.10 \\
\hline
\end{tabular}

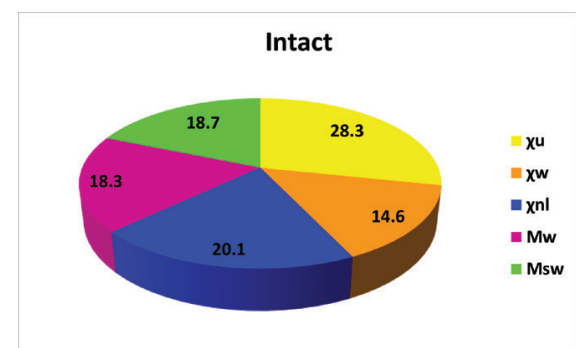

Figure 7. Sensitivity factors for intact ship.

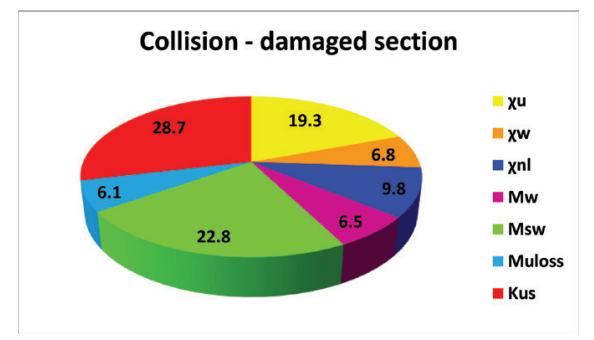

Figure 8. Sensitivity factors for collision (damaged area).

similar ship using Bayesian networks. Failure probabilities calculated by Downes et al. (2007) for different damage scenarios of Aframax tanker read between $8.95 \mathrm{E}-03$ and 1.09E-03. Values presented in Table 7 are in good agreement with those probabilities. Therefore, one may conclude that obtained results are reasonable and in good agreement with other similar researches.

Failure probabilities of damaged ship are conditional values and should be multiplied by the probability that collision or grounding occurs. There are different sources of statistical data about ship accidents. Thus, IMO (2008) provides yearly frequencies of $1.40 \mathrm{E}-02$ and $7.49 \mathrm{E}-03$ for collision/contact and grounding respectively. Prestileo et al. (2013) provide somewhat lower values of 6.52E-03 and 4.64E-03. Downes et al. (2007) used 5.89E-03 and 7.49E-03 for collision and grounding

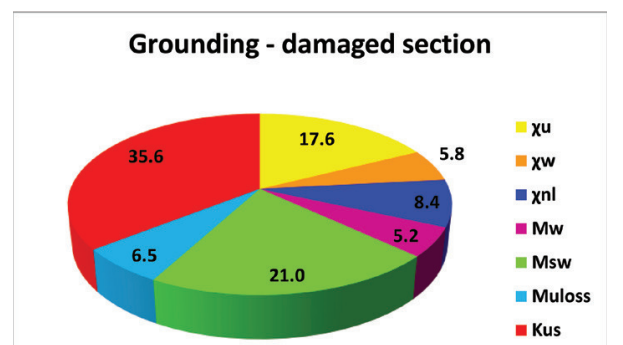

Figure 9. Sensitivity factors for grounding (damaged area).

Table 11. Safety indices for various mean values of $M_{\text {uloss }^{\prime}}$ for damaged ship.

\begin{tabular}{lll}
\hline Damage condition & $\mu$ & $\beta_{f}$ \\
\hline Collision & 3.23 & 2.749 \\
$\quad$ (damaged area) & 3.68 & 2.731 \\
Grounding & 3.81 & 2.357 \\
(damaged area) & 4.51 & 2.334 \\
\hline
\end{tabular}

Table 12. Safety indices for various mean values of relative SWBM $\left(K_{U S}\right)$ for intact and damaged area of damaged ship.

\begin{tabular}{lll}
\hline Damage condition & $\mu$ & $\beta_{f}$ \\
\hline Collision & 0.85 & 2.963 \\
$\quad$ (intact area) & 0.91 & 2.889 \\
Collision & 0.72 & 2.786 \\
$\quad$ (damaged area) & 0.79 & 2.705 \\
Grounding & 0.55 & 2.469 \\
$\quad$ (intact area) & 0.65 & 2.374 \\
Grounding & 0.53 & 2.393 \\
$\quad$ (damaged area) & 0.63 & 2.300 \\
\hline
\end{tabular}

respectively. They proposed also to multiply these values by the probability of the Loss of the Watertight Integrity (LOWI), which reads 0.203 and 0.186 for collision/contact and grounding respectively. Unconditional failure probabilities are hence much lower compared to values specified in Table 7 .

It may be seen from Tables 9 and 10 that for damaged oil tanker SWBM becomes the most important random variable. Random variables $K_{U S}$ and $M_{s w}$ together contribute more than $50 \%$ to the total sensitivity. Variables related to the wave loads and ultimate strength are approximately equally important and their sum is equal to the importance of the SWBM. On the other hand, regarding importance of the individual variables, uncertainty in the ultimate strength calculation $\chi_{u}$, was the most important for the intact ship. For the damaged ship, however, that variable is in the 3rd place, while two variables related to the SWBM become dominant. 
It is also interesting to analyze results for design points, presented in Tables 8-10. At the failure, it is likely that $K_{U S}$ will take value of 1.74 and 2.10 for collision and grounding respectively. This is another evidence of tremendous importance of SWBM after flooding on structural safety of damaged oil tanker. Loss of the ultimate strength at failure reads $5 \%$ and $6 \%$ for collision and grounding respectively.

Parametric study is performed with respect to the mean values of the newly introduced random variables $M_{u l o s s^{\circ} \%}$ and $K_{U S}$. Using values corresponding to $95 \%$ confidence interval, fairly consistent safety indices are obtained. Somewhat higher sensitivity of safety indices to the mean values of input parameters in grounding is obtained than for the collision damage.

Because of the clarity of presentation, only reliability of as-built ship is considered in the present study. If damage occurs when hull structure is corroded, much lower reliability indices are expected. This will be studied in the future work.

\section{CONCLUSION}

The method for calculating failure probability of oil tanker damaged in collision or grounding accident is presented. The proposed approach is consistent with IMO method for reliability assessment of the intact oil tanker. Another characteristic of described method is its simplicity, what is a justified considered large uncertainty of the pertinent random variables involved.

The proposed approach includes random variable representing loss of the ultimate bending moment capacity of damaged ship and also random variable representing increase of the SWBM in damaged condition. Probability distributions of these random variables are based on the random damage characteristics proposed by IMO.

Obtained results indicate huge importance of the SWBM in flooded condition on the structural reliability of damaged oil tanker. Based on that conclusion, it could be recommended to calculate SWBM distribution in damaged condition as the integral part of the verification procedure of the structural integrity of oil tanker regarding accidental limit state.

\section{ACHNOWLEDGEMENT}

This work has been fully supported by Croatian Science Foundation under the project 8658.

\section{REFERENCES}

Bužančić Primorac, B., Ćorak, M and Parunov, J. 2015. Statistics of still water bending moment of damaged ship. Analysis and Design of Marine Structures,
Guedes Soares \& Shenoi (Eds), Taylor and Francis Group., pp. 491-497.

Bužančić Primorac, B. and Parunov, J. 2015. Probabilistic models of ultimate strength reduction of damaged ship. Transactions of FAMENA, (accepted).

Downes, J., Moore, C., Incecik, A., Stumpf, E. and McGregor J. 2007. A Method for the quantitative Assessment of Performance of Alternative Designs in the Accidental Condition, 10th International Symposium on Practical Design of Ships and Other Floating Structures, Houston, Texas.

Guedes Soares, C. and Teixeira, A.P. 2000. Structural reliability of two bulk carrier designs. Mar Struct 2000;13:107-28.

Hussein, A.W. and Guedes Soares, C. 2009. Reliability and residual strength of double hull tankers designed according to the new IACS common structural rules. Ocean Engineering 36, pp. 1446-1459.

IACS. 2000. Recommendation No. 34: standard wave data. Rev. 1.

IMO Revised 2003. Interim guidelines for the approval of alternative methods of design and construction of oil tankers under Regulation 13F(5) of Annex 1 of MARPOL 73/78, Resolution MEPC 2003;110(49), Annex 16.

IMO 2006. Goal-based new ship construction standards, MSC 81/INF6.

IMO 2008. Formal Safety Assessment (FSA)—Crude Oil Tankers, MEPC 58/INF.2.

Kim, D.K., Kim, H.B., Mohd, M.H. and Paik, J.K. 2013. Comparison of residual strength-grounding damage index diagrams for tankers produced by the ALPS/ HULL ISFEM and design formula method. Int. J. Naval Archit. Ocean Eng. 5, pp. 47-61.

Luís R.M., Hussein A.W., Guedes Soares C. 2007. On the Effect of Damage to the Ultimate Longitudinal Strength of Double Hull Tankers. 10th International Symposium on Practical Design of Ships and Other Floating Structures, Houston, American Bureau of Shipping.

Luis, R.M., Teixeira, A.P and Guedes Soares, C. 2008. Longitudinal strength reliability of a tanker hull accidentally grounded. Structural Safety, Volume 31, Issue 3, pp. 224-233.

Muhammad Zubair, M.A. 2013. Residual hull girder strength of asymmetrically damaged ships. Doctoral Dissertation, Graduate School of Engineering, Osaka University.

Paik, J.K., Kim, D.K., Park, D.H. and Kim, H.B. 2011. Modified Paik-Mansour formula for ultimate strength calculations of ship hulls. Advances in Marine Structures, p. 187-202.

Parunov, J. and Guedes Soares, C. 2008. Effects of Common Structural Rules on hull-girder reliability of an Aframax oil tanker. Reliability engineering and System Safety 93. pp. 1317-1327.

Prestileo, A., Rizzuto, E., Teixeira, A.P. and Guedes Soares, C. 2013. Bottom damage scenarios or the hull girder structural assessment. Marine Structures 33, pp. 33-55.

Teixeira, A.P. and Guedes Soares, C. 2010. Reliability assessment of intact and damaged ship structures. Advanced Ship Design for Pollution Prevention, Guedes Soares \& Parunov edts. London: Taylor \& Francis Group, pp. 79-93. 